\title{
Integration with Writing Programs: A Strategy for Quantitative Reasoning Program Development
}

\author{
Nathan D. Grawe \\ Carleton College, ngrawe@carleton.edu \\ Carol A. Rutz \\ CarletonCollege,crutz@carleton.edu
}

Follow this and additional works at: https://digitalcommons.usf.edu/numeracy

Part of the Mathematics Commons, and the Science and Mathematics Education Commons

\section{Recommended Citation}

Grawe, Nathan D., and Carol A. Rutz. "Integration with Writing Programs: A Strategy for Quantitative Reasoning Program Development." Numeracy 2, Iss. 2 (2009): Article 2. DOI: http://dx.doi.org/10.5038/ 1936-4660.2.2.2 


\title{
Integration with Writing Programs: A Strategy for Quantitative Reasoning Program Development
}

\begin{abstract}
As an inherently interdisciplinary endeavor, quantitative reasoning (QR) risks falling through the cracks between the traditional "silos" of higher education. This article describes one strategy for developing a truly cross-campus QR initiative: leverage the existing structures of campus writing programs by placing QR in the context of argument. We first describe the integration of Carleton College's Quantitative Inquiry, Reasoning, and Knowledge initiative with the Writing Program. Based on our experience, we argue that such an approach leads to four benefits: it reflects important aspects of QR often overlooked by other approaches; it defuses the commonly raised objection that QR is merely remedial math; it sidesteps challenges of institutional culture (idiosyncratic campus history, ownership, and inertia); and it improves writing instruction. We then explore the implications of our approach for QR graduation standards. Our experience suggests that once we engaged faculty from across the curriculum in our work, it would have been difficult to adopt a narrowly defined requirement of skills-based courses. The article concludes by providing resources for those who would like to implement this approach at the course and institutional level.
\end{abstract}

\section{Keywords}

quantitative reasoning, program development

\section{Creative Commons License}

cc) (1) (8)

This work is licensed under a Creative Commons Attribution-Noncommercial 4.0 License 


\section{Introduction}

Institutional change is hard. This is never truer than when attempting to establish an interdisciplinary program that has no obvious department to advocate for it. The lack of a departmental advocate has stymied the development of quantitative reasoning (QR) programs. As Steen $(2004$, p. 13-15) points out, "Curricular talk tends to be dominated by disciplines.... With no discipline naturally exercising leadership, there is neither an insistent nor a consistent call to make [QR] a priority of education at the college level."

Carleton College's Quantitative Inquiry, Reasoning, and Knowledge (QuIRK) initiative has experimented with an approach to program development that is designed to overcome these challenges. In particular, we have cooperated extensively with our campus' Writing Program. This cooperation is reflected in almost every aspect of our program from our writing-based assessment strategy, to jointly sponsored professional development workshops that equip faculty to design and teach QR-in-writing assignments, to summer mini-grants that support faculty revising courses to include such assignments. We believe this approach largely explains how our program quickly grew from an unfunded working group of around a dozen faculty members to an initiative engaging more than half of the campus in any given year.

The purpose of this paper is to share our experience integrating QR with writing across the curriculum (WAC). We start with a brief sketch of how we understand what it means to be quantitatively literate. Then we describe in detail how our QR program interacts with our Writing Program and the benefits of this collaboration. Our approach has implications for the design of graduation requirements: having argued for $\mathrm{QR}$ in the context of arguments across the curriculum it would have been difficult to propose a narrowly defined requirement based on skills-based courses. The penultimate section discusses the details of our curriculum-revision process before concluding with a discussion of resources available to aid in the development of similar programs.

\section{Our Understanding of Quantitative Reasoning}

The National Numeracy Network vision sets a goal that students acquire "the power and habit of mind to search out quantitative information, critique it, reflect upon it, and apply it in their public, personal and professional lives."1 Informed by this statement and the broader literature, we have identified at least four facets to QR. First (and maybe most widely recognized), effective implementation of

\footnotetext{
${ }^{1}$ From the National Numeracy Network vision statement. See http://serc.carleton.edu/nnn/about/index.html (accessed May 19, 2009).
} 
$\mathrm{QR}$ requires a basic skill set. Without a nuanced understanding of basic mathematical concepts like ratios, percentages, and averages it is impossible to apply that quantitative knowledge with a high degree of sophistication. This understanding includes an appreciation for both the power and pitfalls of various QR tools. While any two QR advocates will likely not come to complete agreement over the specific skills that are necessary, the general consensus points to a relatively modest set. For instance, Steen (2004 p. 9) argues that QR is "sophisticated reasoning with elementary mathematics more than elementary reasoning with sophisticated mathematics." In a talk given at Carleton College on April 24, 2008, Deborah Hughes-Hallett suggested that the required skills may include:

- Arithmetic, including percentages, graphs

- Estimation

- Elementary probability and statistics

- Basic geometry of measurement (volume, area, perimeter)

- Elementary growth patterns: linear (constant quantity per unit time) and exponential (constant percentage change per unit time).

Second, unlike traditional mathematics, which is intentionally abstract, QR explicitly requires that these skills be implemented in context (De Lange, 2003, p. 80; Richardson and McCallum, 2003, p. 100-102; Steen, 2004, p. 9-10; Bok, 2006, p. 129). Putting this in broader context, the Quantitative Literacy Design Team for Mathematics and Democracy (Steen 2001) wrote, "The test of numeracy, as of any literacy, is whether a person naturally uses appropriate skills in many different contexts" (2001, p. 6). This contextualized problem solving requires students to engage in intellectual transfer, applying lessons learned in one setting to a newly discovered problem. The process includes both the transfer of skills (e.g., calculating geometric growth rates) and the transfer of problemsolving approaches (e.g., considering the size of the effect in addition to its statistical significance when evaluating empirical works). While transfer is among the most challenging of learning goals, Steen (2004, p. 9) underscores the essential nature of context: "personal success in the new information economy requires a new set of problem-solving and behavioral skills that emphasize the flexible application of reasoning abilities."

Third, once students have applied their QR skills to a new problem, they need to communicate the results. More broadly, students come to realize that being able to use QR skills is essential to effective communication across a range of contexts. Perhaps it is easier to see that good QR is essential to effective communication. As data have become ever more accessible, the nature of discourse has changed. Today "numbers [are] the principal language of public argument" according to More or Less, a weekly radio show of the BBC News 
channel. ${ }^{2}$ While we believe this to be true, we would contend that the relationship between writing and QR is reciprocal: sophisticated rhetoric is also important for effective QR. Such rhetoric includes visual presentation through tables and figures in addition to writing with numbers. Recognizing the futility of effective reasoning that cannot be shared, De Lange (2001, p. 77) includes "expressing oneself in a variety of ways in oral, written, and other visual form[s]" among his eight "competencies for [QR]" (see also Brakke 2003, p. 168.)

Finally, even students with the ability to communicate quantitative evidence in context must acquire the habit of mind to approach questions with a quantitative lens (Steen 2001, p. 5; Hughes-Hallett 2003, p. 91). As Steen (2001, p. 2) puts it, students "need a predisposition to look at the world through mathematical eyes." The essential curiosity required is summed up well in the first of Neil Lutsky's "10 Foundational Quantitative Reasoning Questions"3: What do the numbers show? Like any habit of mind, the level of QR sophistication deepens as the student matures (Steen 2004, p. 16-17), allowing for more nuanced interpretations of quantitative evidence. But the first step is always the student's choice, independent of external pressure, to consider how QR might inform a problem.

Combining these four facets, we might summarize our conception of $\mathrm{QR}$ as the habit of mind to consider the power and limitations of quantitative evidence in the evaluation and construction of arguments in personal, professional, and public life. While this statement shares many elements of others' QR definitions, it situates our work in the context of argument in a way that we have found very useful. Simply put, we seek to harness the rhetorical power of numbers.

\section{Key Elements of Our Integrated Quantitative Reasoning and Writing Program}

The integration of QuIRK and Carleton's Writing Program began almost accidentally. In 2004, a small, grassroots group of faculty met to discuss the need for better QR instruction on campus. While each participant had an anecdote to share, the group wanted a more representative understanding of what our students were actually doing in their work. One colleague pointed out that, as part of our graduation requirements, each Carleton sophomore submits a portfolio of 3-5 papers representing work in at least two of the college's four divisions. ${ }^{4}$ She

\footnotetext{
${ }^{2}$ See http://news.bbc.co.uk/2/hi/programmes/more_or_less/1628489.stm (accessed May 19, 2009).

$3 \mathrm{http} / / /$ serc.carleton.edu/quirk/CarletonResources/10questions.html (accessed May 19, 2009).

${ }^{4}$ For more information on Carleton's writing portfolio, consult https://apps.carleton.edu/campus/writingprogram/carletonwritingprogram/ (accessed May 19 2009).
} 
suggested we might better understand how students are using QR (and how we want them to be doing so) by reading a sample of papers drawn from these portfolios. After reading student papers, the group set four learning goals with nine associated outcomes (Table 1).

Table 1

Goals and Outcomes for Quantitative Reasoning in Student Writing

\begin{tabular}{|c|c|}
\hline Goal & Outcomes \\
\hline I. Thinks quantitatively & $\begin{array}{l}\text { 1. States questions and issues under consideration in } \\
\text { numerical terms. } \\
\text { 2. Identifies appropriate quantitative or numerical } \\
\text { evidence to address questions and issues. } \\
\text { 3. Investigates questions by selecting appropriate } \\
\text { quantitative or numerical methods. }\end{array}$ \\
\hline $\begin{array}{l}\text { II. Implements } \\
\text { competently }\end{array}$ & $\begin{array}{l}\text { 4. Generates, collects, or accesses appropriate data. } \\
\text { 5. Uses quantitative methods correctly. } \\
\text { 6. Focuses analysis appropriately on relevant data. }\end{array}$ \\
\hline $\begin{array}{l}\text { II. Interprets and } \\
\text { evaluates thoughtfully }\end{array}$ & $\begin{array}{l}\text { 7. Interprets results to address questions and issues } \\
\text { under consideration. } \\
\text { 8. Assesses the limitations of the methods employed, } \\
\text { if appropriate to the task or assignment }\end{array}$ \\
\hline $\begin{array}{l}\text { IV. Communicates } \\
\text { effectively }\end{array}$ & $\begin{array}{l}\text { 9. Presents and/or reports quantitative data } \\
\text { appropriately }\end{array}$ \\
\hline
\end{tabular}

The experience of reading portfolios coupled with our ongoing reading of the QR literature led us to a conclusion we would not have predicted at the outset of our work: the development of quantitative reasoning on our campus better reflects the totality of QR when it is done in the context of written argument and in cooperation with our Writing Program. This conclusion was quickly reflected in our programming in two ways. First, the QuIRK initiative created a professional development curriculum that mirrored the well-established model of the Writing Program: annual assessment of sophomore portfolios sets an agenda for follow-up professional development workshops and brown-bag discussions that equip faculty to pursue curricular revisions, which in turn generate student work that is subsequently assessed. Second, as we implemented this program, we looked for ways to combine QuIRK events with those of the Writing Program.

This interdisciplinary integration began with assessment. With a better sense of what we hoped to develop in terms of student outcomes, we began work on a 
rubric for assessing the relevance, extent, and quality of QR in student writing. Like the Writing Program, QuIRK gathers faculty and staff each summer to read portfolio papers. However, because we are not interested in student evaluation so much as program evaluation, QuIRK reads only a random sample of roughly 400 papers drawn from portfolios. 5

Following the example of the Writing Program, QR assessment sessions conclude with a discussion of what faculty readers observe after examining a sample of student work. These conversations guide topical programming for professional development workshops and Learning and Teaching Center brownbag seminars during the subsequent year. Equipped by this training, faculty members are given small stipends to create new courses and/or assignments in the following summer. Over time, student work from these new assignments will show up in the writing portfolio for assessment, closing the loop.

This combination of faculty development and assessment can be considered a curriculum of sorts, one in which assessment provides research questions to be tested and improved through programs for professional development. In contrast to typical faculty development sessions offered, say, to new faculty at the beginning of their employment, a curricular approach assumes that (1) pedagogy can be taught to active practitioners; (2) faculty members are willing to exercise the habit of lifelong learning they hope to inspire in their students by sharing their expertise and gaining new skills; (3) faculty members are the smartest, most exciting students that anyone could ever hope to teach-and learn from; and (4) that pedagogy is best evaluated in the context of student work assessed by those invested in student learning: faculty.

Within a cordial partnership, at times QuIRK and the Writing Program operate independently. For all we have in common, we each also have initiativespecific objectives. For instance, QuIRK has sponsored mini-workshops introducing faculty to basic statistics. But the dominant theme has been cooperation rather than competition or even independent co-existence.

\section{Benefits of Integration}

Our experience suggests that cooperation between $\mathrm{QR}$ and writing programs can yield mutual benefits. While we are certain that there are other means of achieving the ends we describe, we share our experience as one way-perhaps one unnoticed way - to establish quickly a QR-across-the-curriculum program.

\footnotetext{
5 A detailed description of our assessment protocol and our current rubric can be found at http://serc.carleton.edu/quirk/Assessment/index.html (accessed May 19, 2009). Future papers will formally present the rubric and its reliability.
} 


\section{Cooperation captures facets of $Q R$ that are easily overlooked.}

As we note above, our understanding of QR includes four facets: basic skills, application in context, communication, and habit of mind. Over the course of our work we have been repeatedly impressed by the way in which integration with the Writing Program has highlighted the latter three of these facets. We will begin with the most obvious of these: communication. To a degree it may be tautological to assert that cooperation with the Writing Program can enhance our ability to teach students to communicate their quantitative arguments. But we mean something far deeper than rhetorical fluency. Where many students perceive the traditional mathematics curriculum as teaching them "the correct way" to solve numeric problems, they readily recognize the subjectivity of rhetorical choices in writing. The reality of $\mathrm{QR}$ arguments is that they involve every bit as much subjectivity as an analysis of a lyric poem. Academic arguments involve construction of meaning based in evidence; QR supplies an important category of evidence for successful argument.

Best (2008) emphasizes this point in his discussion of the "social construction" of numbers. "People have to decide whether to count, what to count, how to go about counting, and how to summarize the results of that counting process" (p. 2). When first presented with this concept, many students initially conclude that numbers fall into two categories: "socially constructed numbers and good numbers" (to use Best's phrasing, p. 3). That is, the subjectivity introduced by social construction is equated with the malicious intent to deceive. But, of course, Best's point is precisely that all numbers are chosen, constructed, and analyzed by people. And as such, they are never beyond question. By asking students to engage QR in the context of written argument, we place them in direct contact with this reality. In their own papers, students must choose which numbers to report (and which to avoid), how to describe those numbers in a way that gives them meaning, and what conclusions can be drawn from the available evidence. As they engage in the process of creating QR-rich arguments, students are forced to recognize themselves as social constructors of numbers. And having engaged in that construction, they are better prepared to see the same social process in quantitative arguments made by others-not because writers are trying to deceive the audience, but because such discretion is unavoidable. When students tell us that data do not speak for themselves - that data are chosen, arranged, and interpreted by human beings - we know that their thinking is changing and the habit of mind we hope to encourage is developing in the context of solving rhetorical problems. 
While the argument is perhaps less obvious, we also find that writing assignments serve as fantastic opportunities for teaching QR in context. In some sense, papers that are written primarily for reasons other than to show explicit QR facility are the most "natural" academic context. Like problems in the real world, paper topics do not usually come to students with a clear directive to consider the ways in which quantitative evidence might bolster an argument. In fact, it is entirely possible that two students could respond to the same paper prompt differently: one choosing a thesis for which QR was inherently essential and the other taking a line of argument for which QR was irrelevant. By teaching QR in the context of argument, we emphasize that we do not encourage QR for its own sake or as a pedagogical fetish. Rather we encourage QR because it is a useful tool that can often help students better understand and express their own ideas concerning issues that they believe are important.

Finally, effective writing assignments usually provide students a great deal of latitude in how they approach a problem. This means we can gain significant insights into their habits of mind by examining the results. Where a student may be quite capable in performing calculations when prompted, she may or may not recognize the power of that skill in a given argument. A student's choice to ignore the relevance of quantitative evidence in forwarding her argument presents a potent teachable moment. Similarly, professional development events that highlight students' choices to avoid QR can be transformative for faculty members. For example, one of our humanities colleagues recently joined us in an assessment session. After several hours carefully considering QR in numerous student papers, he came upon a paper that had been written for one of his own classes. With on appreciation for QR's potency which had been developed through assessment and with direct evidence that student work for his class was lacking in this dimension, he was able to see his own course from a different perspective. He commented, "I now see that I do engage in QR. I just didn't recognize it as such. I've been letting my students slide on this issue, but I won't any longer." This story demonstrates one way that assessment within a faculty development curriculum inspires new thinking.

Another way we expect this new thinking may manifest itself in the classroom is in assignments that require multiple drafts. Whereas the goal is to establish a habit of mind, that habit can be encouraged by having a reader respond to an ineffective first attempt by asking questions - for example, How many? Over what period of time? - to underscore the importance of QR in argument. As faculty sophistication with assignment design and response to student writing improves over time, the likelihood that students are writing and handing in a first draft of an assignment diminishes. In the future we intend to test this hypothesis through textual analysis of assignments that yield good QR-based arguments. 


\section{Cooperation naturally defuses objections that " $Q R$ is just remedial math."}

One of the most common and frustrating objections to QR programs in higher education is that the subject matter is entirely remedial (Madison and Steen, 2009, p. 8). If what we are talking about is believed to be $8^{\text {th }}$-grade work, it will be difficult to get curriculum committees to approve substantial initiatives targeting QR across the curriculum. Steen $(2004$, p. 3) provides a powerful response. He points out, "Although the basic elements of reading and writing are part of the $\mathrm{K}-12$ curriculum, continued growth in both is universally recognized as an essential aspect of college education." Just as we expect reading and writing to develop throughout college, quantitative reasoning

functions at many levels, and no matter how much is accomplished in secondary education there will be much to pursue at the tertiary level that is every bit as sophisticated and subtle as other subjects that students study in higher education. (p. 16-17)

Steen accurately characterizes the attitudes of our Carleton colleagues toward writing at the college level. We have yet to encounter the professor who did not expect students' writing to improve over their college years, no matter how proficient - or deficient - their writing is upon admission. By emphasizing the rhetorical aspects of QR, QuIRK repurposes that good will in support of numeracy. Rather than fighting over whether students should come to college with a full understanding of the importance of the denominator, we engage colleagues in a discussion of the rhetorical advantages our students can gain by asking "who's in the measurement sample." In essence, the tight relationship between our QR initiative and the Writing Program implicitly points colleagues to Steen's argument that whatever skill level students bring to campus can and must be deepened and made more sophisticated.

\section{Cooperation surmounts hurdles of institutional culture.}

The interdisciplinary nature of $\mathrm{QR}$ represents one of the greatest challenges to effective programming. Ideally, the work should be taken up across the curriculum, but lack of cross-disciplinary buy-in can lead to a program that is limited to a single department, often mathematics. Steen $(2004$, p. 18) argues that this result can be very dangerous as students come to see QR as "something that happens only in the mathematics classroom." A similar complaint gave rise to writing-across-the-curriculum (WAC) approaches a generation ago. Students who believed that writing only "counts" in English courses had to accommodate expectations for their writing from everyone, not just English professors. Like Steele and Kiliç-Bahi (2008, p. 2-3), we have found that a well-established WAC 
program prepares the way for a cross-cutting QR initiative. Moreover, explicit coordination with writing programs can support the rapid implementation of truly cross-disciplinary QR initiatives.

At Carleton, this cooperation played out in three ways. First, the institutional culture at every college and university reflects the history and personalities of the faculty and staff on that campus. Policy precedents have been set based on past events, and turf battles have defined invisible (to the uninitiated) boundaries. Any campus-wide initiative must inevitably find a way to navigate this minefield. Fortunately for leaders of QR initiatives, writing program directors have often already completed this task. By working through existing structures, QR programs can reduce this time-consuming task. At Carleton, this was reflected in QuIRK's decision to develop programming that mirrored the established routine of the Writing Program. At times, we even sought joint programming such as "Writing with Numbers" faculty development workshops. By leveraging the institutional knowledge embodied in the Writing Program, we were able to avoid unnecessary and frustrating setbacks caused by inadvertent violations of our campus' norms. We hasten to point out that other curricular initiatives at Carleton, notably those addressing information literacy and visuality, have adopted similar tactics. We are close to claiming a model for across-thecurriculum efforts, and we appreciate the work of writing professionals in showing us the way. ${ }^{6}$

Second, cross-disciplinary initiatives suffer from issues of ownership. For our work to spread throughout the curriculum, we must somehow convince colleagues who do not at first see their courses as QR-relevant to take up this important teaching issue. While those of us involved in the $\mathrm{QR}$ initiative may be able to imagine easily how QR may play out in other professors' courses, providing "constructive advice" on course content is often perilous. Working with the Writing Program allowed us an effective, if indirect, alternative approach. Due to their prior work on writing pedagogy, all faculty would agree that teaching students to write effective arguments is a core mission of the college and is relevant to all fields. If any student were to tell his academic advisor, "I'm avoiding taking Course X because I just don't do writing," we are confident that, to a person, our colleagues would object. Placing QR in the context of effective argument helped professors from all disciplines take ownership of our cause. Because they all want their majors to be able to write persuasive arguments, it was easier to convince them that they should support QR-in-writing than it would have been to get them to support QR alone.

Additionally, portfolio assessment gave us evidence on the relevance and prevalence of QR in student papers throughout the curriculum. We have found it

\footnotetext{
${ }^{6}$ See, for example, Fulwiler and Young 1990.
} 
useful to distinguish between "central" and "peripheral" uses of QR in student work. In the former case, quantitative evidence lies at the heart of the argument being made or the issue being explored. Peripheral use reflects Miller's (2004) contention that "Even for works that are not inherently quantitative, one or two numeric facts can help convey the importance or context of your topic." In Carleton's portfolio, roughly one-third of sampled papers were found to be centrally relevant to $\mathrm{QR}$ and another quarter were deemed peripherally relevant. Written in courses from all four divisions of the college, papers in the peripheral category have been fertile catalysts of faculty discussions about the role of QR in traditionally "non-quantitative" disciplines.

Framed as a necessary rhetorical tool, QR became immediately relevant to the entire campus. Where less than a decade ago QR had few active advocates, our integration with the Writing Program created a critical mass of supporters in less than five years. The numbers provide the evidence. Last academic year, QuIRK events attracted 92 unique faculty participants-over $50 \%$ of the college's teaching full time equivalents (FTE). As one might expect, scientists and social scientists were overrepresented in this group with 57 participants (or $67 \%$ of FTE from those divisions). However, faculty from the arts, literature, and humanities were also well represented (35 participants or $41 \%$ of FTE). Counting last year and the first quarter of this year, we have involved $61 \%$ of FTE- $72 \%$ in the sciences and social sciences and $51 \%$ in the arts literature and humanities.

To be sure, attending a brown-bag seminar or even a professional development workshop demonstrates (by itself) a relatively low level of commitment. But our experience suggests that our writing-centered approach generates deeper engagement as well. Last summer we supported 22 faculty members as they revised courses to enhance $\mathrm{QR}$ instruction. Of those, eight taught in the arts, literature, or humanities. As a result, we are increasingly confident that our colleagues in all divisions will not accept an advisee's explanation that, "I'm avoiding taking Course X because I just don't do numbers."

Finally, collaboration with the Writing Program has helped us surmount institutional inertia. In our experience, the cooperative approach addressed problems of both money and participation. When our initiative began its work in 2004, we had no source of dedicated funding. Furthermore, grant proposal processes have become increasingly competitive, requiring that initiatives show results before they receive support. By tapping into the resources of the Writing Program, we were able to move forward in our programming without a dedicated budget line. Fortunately, QuIRK has subsequently attracted grant support. And today the Writing Program benefits from our work; QUIRK is delighted to reciprocate. Even if funding were not an issue, it would have been very difficult to move forward on our own due to faculty time constraints. Faculty members 
only have so much time to work on pedagogical issues, and it seems unlikely we would have been successful casting our work as "yet another thing someone is asking you to do." The Writing Program was already established on campus, drawing a large fraction of professors to its events. Presenting QR in the context of argument made QuIRK's programming a complement to work our colleagues were already engaged in. In essence, we were able to change how colleagues thought about QR without changing how they spent their time. We believe this was a key factor in generating broad involvement in a short span of time.

\section{Cooperation improves writing instruction.}

No matter how beneficial the cooperative approach may be for a $Q R$ initiative, writing programs must be convinced that integration serves their goals as well. One only need examine the front page of the New York Times to find examples to support that case. Whether debating a bailout for US automakers, considering the benefits of statins for a broad population, or predicting the outcome of a US Senate race recount, ours surely is a "world awash in numbers" (Steen 2001, p. 1). And in that world, effective writers must consider technical, rhetorical, and ethical issues surrounding the use of numbers in text, table, and chart.

Some aspects of writing with numbers are merely specific cases of broader rhetorical points. For instance, the use of data is but one of many ways an author might assert a claim to authority. Similarly, the debate over whether to scale graphs to include 0 on the $y$-axis (see Wainer, 2005, p. 28-38) is part of a much more general discussion surrounding the loss of context that results whenever an image or text is cropped or edited. Likewise, the expectation that students use actual numbers rather than making reference to "many," "some," "infrequent," and other weak quasi-numerical terms might be seen as an application of universal demands for precision in language or evidence to support claims. By explicitly identifying the QR-specific applications of these principles, writing programs can bolster their relationships with traditionally quantitative disciplines. Clearly, this practice would support writing programs' missions.

Other issues are more specific to the art of writing with numbers. For instance, students must learn to choose the most effective chart type to present their argument. Then the chart must be integrated effectively into the text. Recognizing that these skills transcend general writing fluency, a substantial literature has developed around these QR-specific issues (e.g., Few, 2004; Miller, 2004; Tufte, 2001; Wainer, 2005). As writing programs consider the new composition demands our students will face in the $21^{\text {st }}$ century, QR will surely be among them. As Max Frankel (1995) of The New York Times Magazine colorfully writes, "Deploying numbers skillfully is as important to communication as deploying verbs." 


\section{Implications for QR Graduation Requirements}

Like so many other institutions of higher education, Carleton has moved toward following Bok's (2006) suggestion of a QR graduation requirement. But the nature of our new $\mathrm{QR}$ requirement differs substantially from the models adopted elsewhere. ${ }^{7}$ Our experience suggests that the integration of QR with argument has implications for graduation requirements that should be considered before imitating our method. Furthermore, any interdisciplinary or multidisciplinary collaboration may well speak to reimagining core skills and outcomes-an important and largely unforeseen result of the Carleton WAC/QR experience to date.

Our curriculum review began in earnest in early 2008 when the Dean of the College convened three teams of faculty to propose new general education requirements. Each team essentially began with a blank slate. They would design, from scratch, a general education model. The three plans were presented to the faculty as a whole in the fall of 2008. Then, after discussion, the plans were revised and combined into two alternatives that were considered by the faculty in winter 2009.

While we knew that QuIRK would be able to lobby to add a QR requirement after the curricular design teams had completed their work, it was clear that it would be much easier to institute a standard if it were included in the teams' initial reports. Nevertheless, QuIRK had little control over the design teams' deliberations. The dean crafted each team to be more or less representative of the faculty as a whole. In particular, he did not place all the advocates of a "skillsbased" model on one team and all of the supporters of "traditional silos" on another. Moreover, only one team included a member of QuIRK's steering committee (although that one representative happened to be Neil Lutsky, the initiative's founding director). In short, QuIRK lacked committed advocates on two of the three teams. Moreover, QuIRK faculty had not led an active drive for a $\mathrm{QR}$ requirement. The committee had no official position on a $\mathrm{QR}$ requirement and had not openly lobbied for such a graduation standard at faculty meetings or other faculty gatherings.

Despite these liabilities, our strategy of making QR relevant across the curriculum was successful: all three of the curriculum design teams recommended that the College add a QR requirement. Two of the three explicitly deferred to QuIRK in the design of the requirement. Far from having to fight for recognition

\footnotetext{
${ }^{7}$ For example: Wellesley (see http://www.wellesley.edu/QR/introduction.htm); Yale (http://www.yale.edu/cyce/report/cycereport.pdf, especially p.15-20 and Appendix 1); Macalester (Bressoud 2009).
} 
of $\mathrm{QR}$ as an essential undergraduate learning goal, our efforts to tie $\mathrm{QR}$ with argument as relevant throughout the curriculum led to quick consensus that some form of a $\mathrm{QR}$ requirement be included in the new standards.

QuIRK's steering committee was subsequently asked to recommend a detailed requirement. We considered three possible components for our graduation standards:

- a QR methods course that would cover basic statistics and the social construction of numbers;

- designated QR courses that emphasized QR applications throughout the course; and

- designated "QR encounters" that included a substantial assignment or course module demonstrating and teaching the use of QR in context.

Having emphasized the contextual and rhetorical aspects of QR for almost four years, the committee decided against the methods requirement. While there were differences of opinion, many committee members felt such a requirement would reinforce students' and colleagues' narrow conceptions of the discipline. In particular, it seemed likely that few departments could offer a course including extensive statistical methods. The lack of a methods course in the proposed requirements clearly constrains our program in some ways. We hope that by exposing students to the power of numbers, many will seek out methods training, continuing a trend we've seen since QuIRK's inception. Readers should think seriously about the tradeoff between across-the-curriculum participation and the importance of a strong methods emphasis when considering adoption of QuIRK's model of programming.

A single QR-rich course seemed little better. By scattering such courses throughout the course catalogue we could signal the many contexts in which quantitative literacy is relevant. But the single-course requirement might suggest to students that $\mathrm{QR}$ is something learned at one point in time rather than developed through repeated application. Ultimately, we recommended that students take three "QR encounters." By reducing the extent of $Q R$ in qualifying courses, we expanded the number of courses with a $\mathrm{Q}$ designation (signaling the broad applicability of this skill) and increased the odds that our colleagues would accept a multi-course requirement.

The committee further recommended a change to the College's writing portfolio requirement. Recognizing the importance of $\mathrm{QR}$ to effective writing in the $21^{\text {st }}$ century, QuIRK suggested that we require students include one paper demonstrating their ability to "write with numbers." This change will reflect the full integration of QR and writing on campus: just as our understanding of $\mathrm{QR}$ reflects the relevance of rhetoric, so too our understanding of writing proficiency now points toward the importance of $\mathrm{QR}$. 
In February, the Education and Curriculum Committee sent a proposed curriculum revision to the full faculty. The proposal included the QR requirement as designed by QuIRK without revision. Given that the proposed revision generally reduced graduation requirements, we believe that situating $\mathrm{QR}$ in the context of argument was key in our efforts to forward a new QR requirement. In February, the Education and Curriculum Committee sent a proposed curriculum revision to the full faculty that included the $\mathrm{QR}$ requirement as designed by QuIRK. In two months of faculty discussion, the QR proposal faced little opposition and was ultimately passed by faculty vote as part of the new curriculum.

\section{Resources for Implementation}

Recognizing the novelty of our conception of $\mathrm{QR}$, we conclude by providing resources that may be helpful to those wishing to imitate our approach. Our experience has convinced us that engaging faculty directly in the assessment of student work provides the impetus for curricular change. The examination of QR in student work also offers us the chance to show colleagues in traditionally nonquantitative disciplines how QR may be relevant to their courses. Our assessment protocol, ${ }^{8}$ including the scoring rubric, can be found on our Web site. In 2009 and 2010, we will complete four feasibility studies to learn better how our rubric can be adapted to fit the needs of a diverse set of institutions. When complete, results from those studies will be posted on the page. More recently, the Association of American Colleges and Universities (AAC\&U) has developed a set of "metarubrics" for the assessment of their Essential Learning Outcomes." One of these outcomes is quantitative literacy. In 2009 this new rubric will be tested on a variety of campuses and revised.

Some have wondered whether an institution needs to have a writing portfolio to employ our rubric. That is certainly not necessary. (In fact, several of the feasibility studies will be completed at institutions without portfolios.) All that is needed is a sample of student work. One way to proceed is to identify courses to sample. Arrange to have a student worker meet the faculty member at his or her office immediately after class on the day papers are due. If copies can be made within an hour, colleagues are usually willing to allow student work to be taken from their course. Of course, the Institutional Review Board (IRB) should be consulted prior to collecting student work. While most IRBs set a lower bar for educational assessment efforts, we recommend thinking expansively about

\footnotetext{
${ }^{8}$ See http://serc.carleton.edu/quirk/Assessment/index.html (accessed May 19, 2009).

${ }^{9} \mathrm{http} / / / \mathrm{www}$. aacu.org/value/metarubrics.cfm (accessed May 19, 2009)
} 
possible uses for the collected data, including empirical studies of QR use and proficiency.

Having raised awareness, professional development workshops equip teachers to change their courses and assignments. QuIRK's professional development program for the past five years is described on our Web site. ${ }^{10}$ The section detailing our workshops includes the agenda and materials for each of 11 events. Topics include Writing with Numbers, Teaching with Cases, Writing with Images, and Medical Research and Personal Health. Where possible we have teamed up with other campus initiatives (in particular, Visuality, Information Literacy, Environmental and Technology Studies, and Ethics). While this coordination has required compromise in setting the workshop agenda, it has allowed us to reach a wider audience: an intentional effort to reproduce some of the success we have already experienced working with the Writing Program.

Faculty who have been motivated to revise courses to include a writing-withQR assignment can learn more about best practices in such assignments in a series of essays written by John Bean, well-known author of an important faculty development work, Engaging Ideas (1996). The "Quantitative Writing" Web page $^{11}$ on the NNN Web site includes a link to writing-with-numbers assignments including examples from American studies, biology, chemistry, economics, English, environmental studies, fine arts, geography, geosciences, history, mathematics, physics, political science, psychology, and sociology. While the assignments currently number 43, the collection will continue to grow with ongoing revisions at Carleton and elsewhere contributing to the group. Alternatively, a smaller collection is available through links on the "Examples of QR-rich courses at Carleton" Web page ${ }^{12}$ of the QuIRK Web site. These courses each include multiple writing-with-numbers assignments.

\section{Conclusion}

Designing an effective QR program is inherently challenging due to the interdisciplinary nature of the subject. In Our Underachieving Colleges, Derek Bok (2006, p. 134) argues

$[\mathrm{N}]$ umeracy is not something mastered in a single course. The ability to apply quantitative methods to real-world problems requires a facility and an insight and intuition that can be developed only through repeated practice. Thus quantitative material needs to permeate the curriculum, not only in the sciences but also in the social sciences and, in appropriate

\footnotetext{
${ }^{10}$ See http://serc.carleton.edu/quirk/ProgramDesign/pd_curriculum.html (accessed May 19, 2009).

${ }^{11} \mathrm{http}: / /$ serc.carleton.edu/nnn/quantitative_writing/index.html (accessed May 19, 2009).

${ }^{12} \mathrm{http}: / /$ serc.carleton.edu/quirk/CarletonResources/qr_courses.html (accessed May 19, 2009).
} 
cases, in the humanities, so that students have opportunities to practice their skills and see how useful they can be in understanding a wide range of problems.

This all sounds very exciting until we as leaders of QR initiatives realize that it means our success is dependent on the actions of colleagues from across the campus - colleagues who do not immediately see the relevance of $\mathrm{QR}$ to their courses. How can we surmount this challenge?

In this article we have presented one answer based on our experience with Carleton's QuIRK initiative: cooperate with existing writing programs. On most campuses, these programs are well established and have extensive faculty buy-in. By placing $\mathrm{QR}$ in the context of argument, we can leverage the assets of the writing program to overcome institutional barriers, develop broad faculty support, and sidestep cultural inertia that plagues new initiatives. And, we argue, all of this can be done while reflecting facets of $\mathrm{QR}$ that would otherwise be underrepresented in programming.

\section{Acknowledgments}

We are grateful to Neil Lutsky, Liz Ciner, and several anonymous referees for helpful comments on this work. All remaining errors are our own. This work was supported by generous grants from the W. M. Keck Foundation and the National Science Foundation (\#DUE-0717604).

\section{References}

Bean, John C. 1996. Engaging Ideas: The Professor's Guide to Integrating Writing, Critical Thinking, and Active Learning in the Classroom. San Francisco: Jossey-Bass Publishers.

Best, Joel. 2008. Birds - dead and deadly: Why numeracy needs to address social construction. Numeracy, 1(1): Article 6. http://dx.doi.org/10.5038/ 1936-4660.1.1.6 (accessed May 19, 2009).

Bok, Derek. 2006. Our Underachieving Colleges: A Candid Look at How Much Students Learn and Why They Should Be Learning More. Princeton, NJ: Princeton University Press.

Brakke, David F. 2003. Addressing societal and workforce needs. In Quantitative Literacy: Why Numeracy Matters for Schools and Colleges, ed. Bernard L. Madison and Lynn Arthur Steen, p. 167-169. Princeton, NJ: National Council on Education and the Disciplines. http://www.maa.org/ql/pgs167_169.pdf (accessed May 19, 2009). 
Bressoud, David. 2009. Establishing the Quantitative Thinking Program at Macalester Numeracy, 2(1): Article 3. http://dx.doi.org/10.5038/19364660.2.1.3 (accessed May 19, 2009).

De Lange, Jan. 2003. Mathematics for literacy. In Quantitative Literacy: Why Numeracy Matters for Schools and Colleges, ed. Bernard L. Madison and Lynn Arthur Steen, p. 75-89. Princeton, NJ: National Council on Education and the Disciplines. http://www.maa.org/ql/pgs75 89.pdf (accessed May 19, 2009).

Few, Stephen. 2004. Show Me the Numbers: Designing Tables and Graphs to Enlighten. Oakland, CA: Analytics Press.

Frankel, Max. 1995. Word and Image; Innumeracy. New York Times, March 5.

Fulwiler, Toby, and Art Young. 1990. Programs That Work: Models and Methods for Writing Across the Curriculum. Portsmouth, NH: Boynton/Cook Heineman.

Hughes-Hallett, Deborah. 2003. The role of mathematics courses in the development of quantitative literacy. In Quantitative Literacy: Why Numeracy Matters for Schools and Colleges, ed. Bernard L. Madison and Lynn Arthur Steen, p. 91-98. Princeton, NJ: National Council on Education and the Disciplines. http://www.maa.org/q1/pgs91_98.pdf (accessed May 19, 2009).

Hughes-Hallett, Deborah. "How Do We Teach Quantitative Reasoning? Foster a Curricular Conspiracy." Carleton College Perlman Center for Teaching and Learning seminar, April 24, 2008.

Madison, Bernard L. and Lynn Arthur Steen. 2009. Confronting challenges, overcoming obstacles: A conversation about quantitative literacy. Numeracy, 2(1): Article 2. http://dx.doi.org/10.5038/1936-4660.2.1.2 (accessed May 29, 2009).

Miller, Jane E. 2004. The Chicago Guide to Writing about Numbers. Chicago: University of Chicago Press.

Richardson, Randall M. and William G. McCallum. 2003. The third R in literacy. In Quantitative Literacy: Why Numeracy Matters for Schools and Colleges, ed. Bernard L. Madison and Lynn Arthur Steen, p. 99-106. Princeton, NJ: National Council on Education and the Disciplines. http://www.maa.org/ql/pgs99_106.pdf (accessed May 19, 2009).

Steele, Benjamin and Semra Kiliç-Bahi. 2008. Quantitative literacy across the curriculum: A case study," Numeracy, 1(2): Article 3. http://dx.doi.org/10. 5038/1936-4660.1.2.3 (accessed May 29, 2009).

Steen, Lynn Arthur, ed. 2001. Mathematics and Democracy: The Case for Quantitative Literacy. Washington, DC: Woodrow Wilson National Fellowship Foundation. http://www.maa.org/ql/mathanddemocracy.html (accessed May 29, 2009). 
- 2004. Achieving Quantitative Literacy: An Urgent Challenge for Higher Education. Washington, DC: Mathematical Association of America.

Tufte, Edward R. 2001. The Visual Display of Quantitative Information. Cheshire, CT: Graphics Press.

Wainer, Howard. 2005. Graphic Discovery: A Trout in the Milk and Other Visual Adventures. Princeton, NJ: Princeton University Press. 